\title{
Parental Deprivation and Adolescents Mental Health
}

\author{
Dr. Smritikana Mitra Ghosh ${ }^{1 *}$
}

\section{ABSTRACT}

The aim of the present investigation was to study the impact of parental deprivation on mental health of adolescents. The study was conducted on 80 adolescents, there were 40 from parentally deprived and 40 students from non - deprived. Their age ranged between 16 to 18 years. They were belonging to Ranchi town. Mental Health Battery (2008) by Singh and Sengupta were used to measure Mental Health of the respondents. ' $t$ ' test was applied to check significance of difference between means of the two groups. The finding of the study revealed that there was significant influence of parental deprivation on Mental Health. Non-deprived adolescents had significantly better mental health than parentally deprived adolescents.

Keywords: Parental Deprivation, Non-Deprived Adolescents

Family is the primary and smallest unit of the social institutions and the parents are the primary socializing agents. In a good home, parents and other members of the family are loving and caring and help in enabling the child to adjust well in the home as well as outside. It has been found that successful children come from homes where a positive wholesome relationship exists between them and their parents. The family is a complex social group where different relationships develop among the members. As the child's relationship with his parents based upon affection and discipline give him training in reacting to superiors, so do the relation with siblings give him framing in reactions towards his equals. Here one finds the development of friendship dominance and leadership co-operation and competition. There are a range of behaviors and associated emotions exchanged between parents and their adolescent offspring: Some of these exchanges involve positive and healthy behaviors and others involve the opposite; some of the outcomes for adolescent development of these exchanges reflect good adjustment and individual and social success, whereas other outcomes reflect poor adjustment and problems of development.

\footnotetext{
${ }^{1}$ Ph.D, Psychology, Ranchi University

*Responding Author

(C) 2016 I S Ghosh; licensee IJIP. This is an Open Access Research distributed under the terms of the Creative Commons Attribution License (http://creativecommons.org/licenses/by/2.0), which permits unrestricted use, distribution, and reproduction in any Medium, provided the original work is properly cited.
} 


\section{Concept Of Parental Deprivation}

Parental deprivation is a subject of considerable importance in our own day, especially to those concerns with social welfare. The psychologists insist that parental loss has a significant effect on the development of the personality, and this is true whether it came about by rejections, estrangement - as through divorce or by death. At the present time something like a sixth or more of all children under the age of 18 may well have suffered departure of a parent from the home. It is probable that less than a quarter of these parentally deprived persons have actually lost father or mother or both because of death. Deprived of a natural family life, children in destitute horns are maladjusted, have low super ego strength, lack acceptance of group moral standards, disregard roles, have low mental capacity, and are unreflective. Deprived groups of children and young adolescents, exposed to an unsupportive social climate, often fail to adjust to environmental demands. This further interferes with the realization of their potential. Researchers have as yet documented the dysfunctional health consequences of deprivation. The death of a parent or sibling (family bereavement) is associated with mental health problems in approximately, $25 \%$ of the affected children. However, it is still unknown whether mental health problems of family bereaved adolescents are predicted by pre-existing mental health problems, pre-loss family functioning, or multiple bereavements. The death of a parent during adolescence is a tragic, irreversible loss, which leads to elevated levels of psychological distress. Parentally bereaved adolescents are at risk for developing internalizing disorders. Adolescents who overcome bereavement without developing serious mental health problems may have certain protective factors in common. Theoretical and clinical accounts suggest that family functioning, including family organization, cohesion, communication and role differentiation, pre- and postbereavement is important for the effect of parental bereavement on mental health problems.

\section{Concept Of Mental Health}

Mental Health simply not the absence of mental illness, but is a state of emotional and social wellbeing in which the individual can cope with the normal stresses of life and achieve his or her potential. It is defined as a state of well-being in which every individual realizes his or her own potential, can cope with the normal stresses of life, can work productively and fruitfully, and is able to make a contribution to her or his community. Burnham who emphasized the importance of integration or wholeness of personality said, a mentally healthy person is one who has a wholesome balanced personality free from schisms and inconsistencies, emotional and nervous tensions, disorders and conflicts. Mental health describes a level of psychological well-being, or an absence of a mental disorder. From the perspective of 'positive psychology' or 'holism', mental health may include an individual's ability to enjoy life, and create a balance between life activities and efforts to achieve psychological resilience. Mental health can also be defined as an expression of emotions, and as signifying a successful adaptation to a range of demands.

\section{REVIEW OF LITERATURE}

Parental deprivation and mental health are interrelated issue. The role of parent-child relationship in personality development of a child implies relationship with both mother and father, the 
relationship with mother has the most vital effect on the child. According to Kendler et al. (2002), several studies have suggested that the association between parental separation and mental disorder might occur because parental loss may be a marker of other factors, such as genetic liability or family discord, which could actually represent the true risk factors. Studies consistently point to the importance of higher levels of caregiver warmth and lower levels of caregiver mental health problems in protecting against negative outcomes from the death of a primary caregiver (Lin et.al, 2004; Luecken et. al, 2009 \& Haine et. al, 2006). Reviews of studies from various countries on childhood bereavement following parental death (Dowdney, 2000; Haine et al., 2008) report that children in this situation do experience a wide range of emotional and behavioural symptoms often classified as nonspecific disturbance. According to Dowdney mental health problems of the adolescent before bereavement may constitute an important risk factor because stress caused by the loss can aggravate pre-existing mental health problems. Furthermore, children who lose a parent or a sibling are at risk for the same mental health problems.

\title{
Hypotheses
}

- The level of mental health will vary in parentally deprived and non-deprived adolescents.

- Parentally deprived adolescents will show poor mental health status than non-deprived adolescents.

\section{Research Sample}

The sample consisted of 80 adolescents, out of which 40 served as experimental group (parentally deprived) and 40 as normal control (non -deprived). Subjects of parentally deprived group were selected from different orphanage situated in Ranchi and non - deprived group was selected from different high schools of Ranchi town. All of these ranging age - group 14 to 16 years.

\section{Variables}

- $\quad$ Dependent variable: Mental Health.

- Independent variables: Parentally Deprived and Non-Deprived adolescents.

\begin{abstract}
Measure
Mental Health Battery (MHB) - Mental health battery was developed by Singh \& Sen Gupta (2008). MHB intends to assess the status of mental health of persons in the age range of 13 to 22 years. As it is a battery of six tests. There are set of 130 items in the Mental Health Battery with six dimensions-emotional stability (ES), over all adjustment (OA), Autonomy (AY), security Insecurity (SI), self - concept (SC) and Intelligence (IG). Total Mental Health Scores were indicative of the Mental Health Status of the individual as a whole. The answers of items in each part which tally with the answers given in the scoring key would be given a score of +1 . If they don't tally, they will be given a score of zero.
\end{abstract}




\section{Statistical Analysis}

In the present study Percentage, Mean, S.D and t-test was applied for statistical analysis of data.

\section{RESULTS AND DISCUSSION}

Table-1: Number and percentage of parentally deprived and non-deprived adolescents having poor, average and good level of Mental Health.

\begin{tabular}{|c|c|c|c|c|c|c|c|}
\hline \multirow{2}{*}{ Group } & \multirow{2}{*}{$\mathbf{N}$} & \multicolumn{2}{|c|}{ Poor } & \multicolumn{2}{|c|}{ Average } & \multicolumn{2}{|c|}{ Good } \\
\hline & & $\mathbf{N}$ & $\%$ & $\mathbf{N}$ & $\%$ & $\mathbf{N}$ & $\%$ \\
\hline $\begin{array}{l}\text { Parentally } \\
\text { Deprived }\end{array}$ & 40 & 20 & 50 & 12 & 30 & 8 & 20 \\
\hline Non-Deprived & 40 & 0 & 0 & 5 & 12.5 & 35 & 87.5 \\
\hline
\end{tabular}

Figure-1: Percentage of poor, average and good Mental Health among parentally deprived adolescents

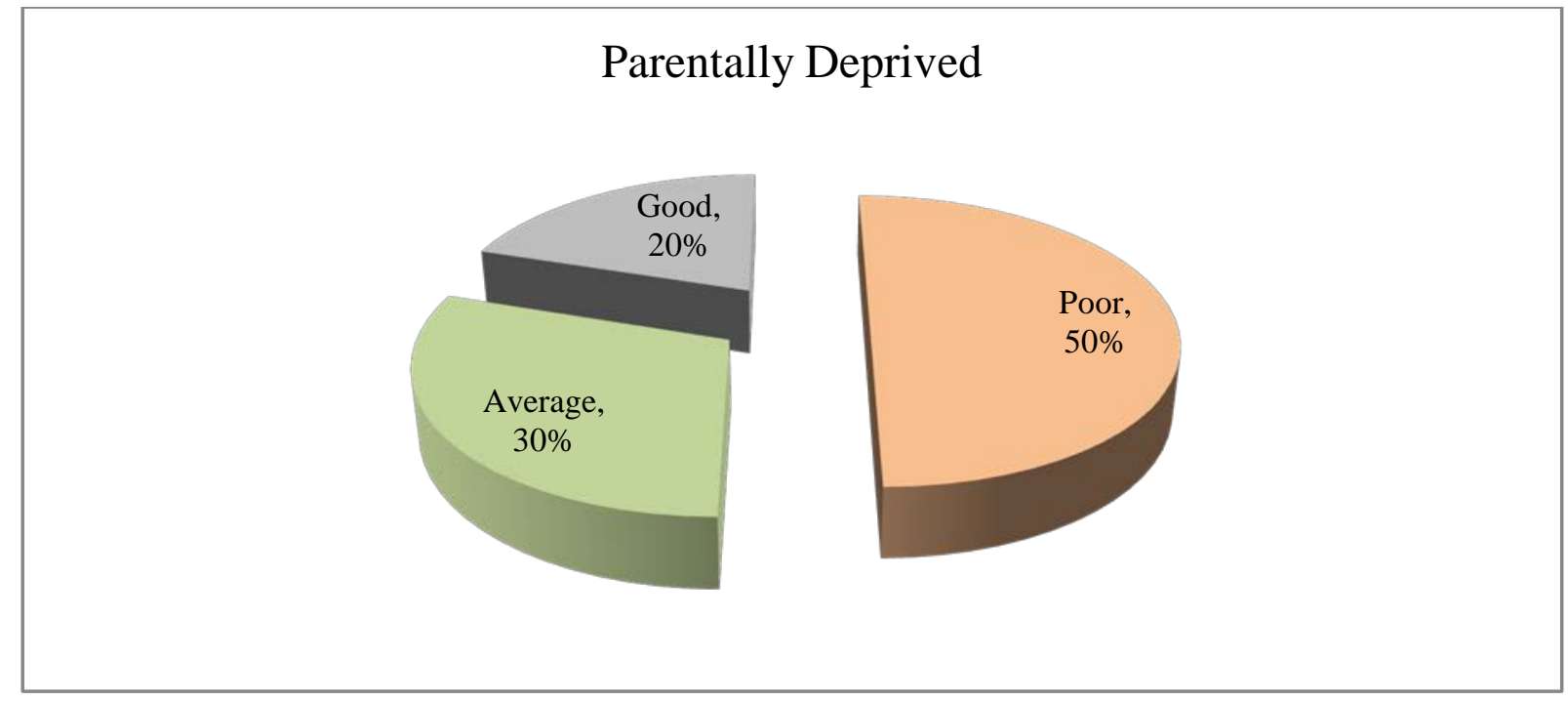


Figure-2: Percentage of poor, average and good Mental Health among non-deprived adolescents

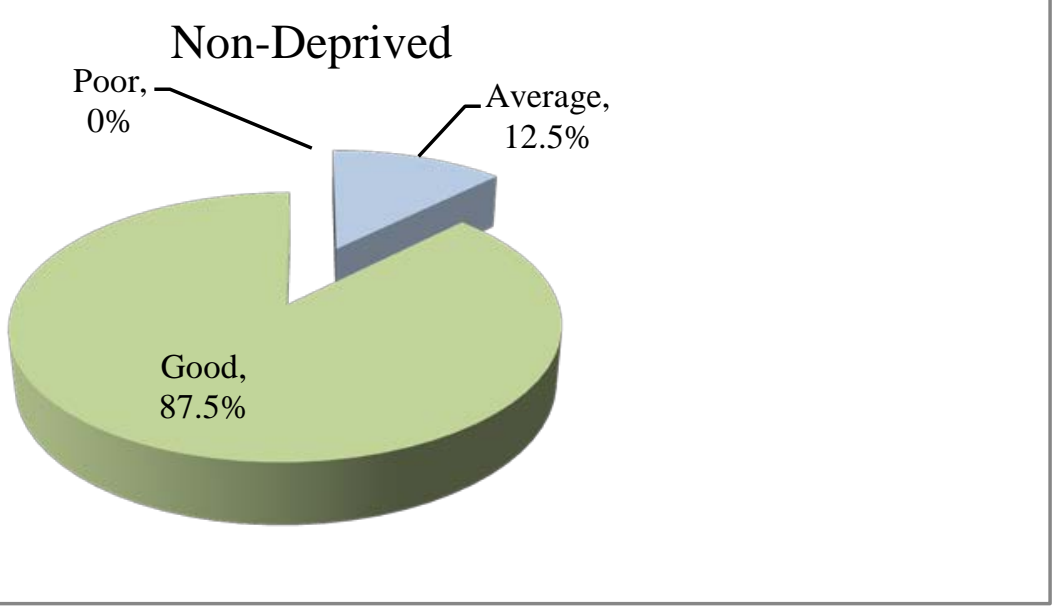

A look at the figures reported in table 4.1 revealed the following points:

- The percentage of good mental health was the higher in non-deprived group $87.5 \%$ than parentally deprived group $20 \%$.

- Percentage of average mental health was higher in 30\% parentally deprived group than non-deprived group $12.5 \%$.

- High percentage of 50\% parentally deprived group showed poor level of mental health.

Table-2: Comparison between parentally deprived and non-deprived group in Mental Health

\begin{tabular}{|l|l|l|l|l|l|}
\hline Groups & N & Mean & SD & t value & P value \\
\hline Parentally Deprived & 40 & 71.95 & 8.44 & & \\
\cline { 1 - 3 } Non-Deprived & 40 & 93.21 & 10.08 & 10.27 & 0.01 \\
\hline
\end{tabular}

Figure-3: Mean scores of parentally deprived and non-deprived group in Mental Health

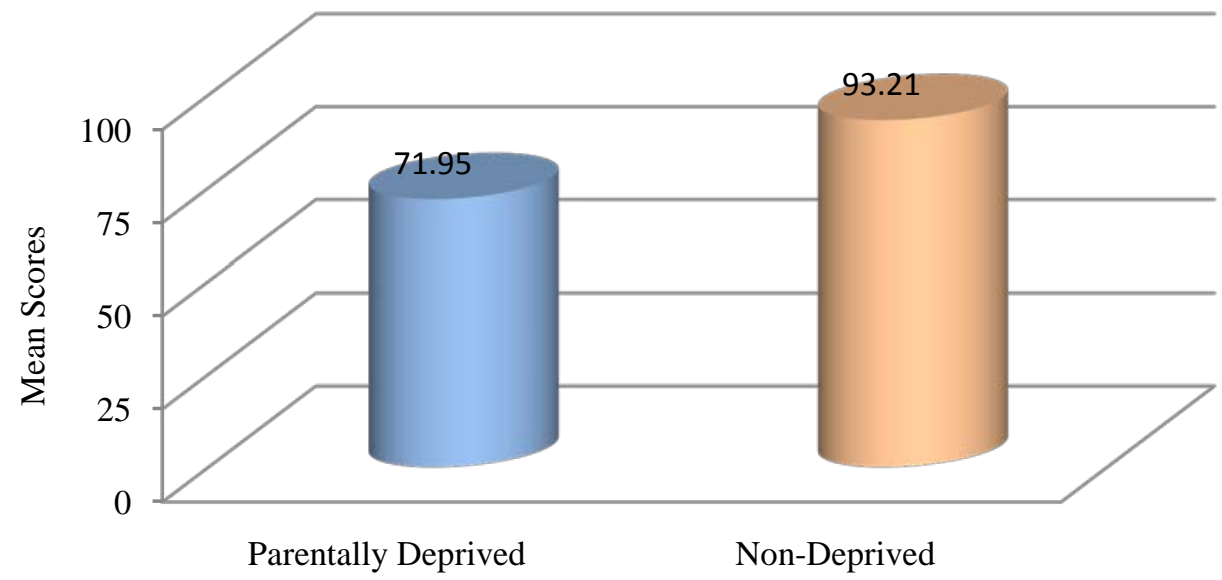


Mean scores (Table 4.2 \& Figure 4.3) showed that the parentally deprived and non-deprived adolescents differ significantly in their mental health. Non- deprived group obtained higher mean scores ( $M=93.21)$ than their counterpart parentally deprived group ( $M=71.95)$. Obtained tratio between the means was 10.27 which were significant at 0.01 level of significance. Hence, the hypothesis "Parentally deprived adolescents will show poor mental health status than nondeprived adolescents” was accepted. Family bereavement puts adolescents at risk for mental health problems in comparison to non-bereaved peers.

\section{CONCLUSIONS}

Non-deprived adolescents showed good mental health than parentally deprived adolescents.

\section{REFERENCES}

Dowdney, L. (2000). Annotation: Childhood bereavement following parental death. Journal of Child Psychology and Psychiatry, 41(7), 819-830.

Haine, R.A., Ayers, T.S., Sandler, I.N. \& Wolchik, S.A. (2008). Evidence-based practices for parentally bereaved children and their families. Professional Psychology: Research and Practice, 39(2), 113-121.

Haine, R.A., Wolchik, S.A., Sandler, I.N., Millsap, R.E. \& Ayers, T.S. (2006). Positive Parenting as a Protective Resource for Parentally Bereaved Children. Death Studies, 30(1), 1-28.

Kendler, K.S., Sheth, K., Gardner, C.O \& Prescott, C.A. (2002).Childhood parental loss and risk for first-onset of major depression and alcohol dependence: the time-decay of risk and sex differences. Psychological Medicine. 32:1187-1194.

Lin, K.K., Sandler, I.N., Ayers, T.S., Wolchik, S.A. and Luecken, L.J. (2004). Resilience in Parentally Bereaved Children and Adolescents Seeking Preventive Services. Journal of Clinical Child and Adolescent Psychology, 33(4), 673-683.

Luecken, L.J., Kraft, A., Appelhans, B.M., and Enders, C. (2009). Emotional and cardiovascular sensitization to daily stress following childhood parental loss, Developmental Psychology, 45 (1), 296-302.

S Ghosh (2014) Emotional Intelligence and Academic Achievement among Advantage and Disadvantage Children, International Journal of Indian Psychology, Volume 2, Issue 1 (No.4) , dip: B00270V2I12014

S Ghosh (2015) Job Satisfaction among Government and Private School Teachers of Ranchi, International Journal of Indian Psychology, Volume 2, Issue 2 (No. 4), dip: B00369V2I22015

How to cite this article: S Ghosh (2016), Parental Deprivation and Adolescents Mental Health, International Journal of Indian Psychology, Volume 3, Issue 3, No. 7, DIP: 18.01.122/20160303, ISBN: 978-1-365-12175-3 